Dr Tom Ricketts at the Sheps Center, University of North Carolina, gave us the original idea for carrying out these analyses.

Funding: NPCRDC is funded by the Department of Health.

The views expressed in this paper are those of the authors and not necessarily those of the Department of Health.

Competing interests: None declared.

1 Secretary of State for Health. The new NHS. London: Stationery Office, 1997. (Cm 3807.)

2 NHS Executive. The new NHS: a national framework for assessing performance. Leeds: NHSE, 1998

3 Arnold J, Zuvekas A. Using health outcomes to evaluate the primary care system: a manual. Washington: US Department of Health and Human Services, Public Health Service, Health Resources and Service Administraices, Public
tion, 1989.

4 Billings J, Hasselblad V. Use of small area analysis to assess the performance of the outpatient delivery system in New York city: a preliminary study. New York: Health System Agency of New York, 1989.

5 Massachusetts Division of Health Care Finance and Policy. Improving primary care: using preventable hospitalization as an approach. Boston: Division of Health Care Finance and Policy, 1995.

6 Lambrew JM, DeFriese GH, Carey TS, Ricketts TC, Biddle AK. The effects of having a regular doctor on access to primary care. Med Care 1996:34:138-51.

7 Begley CE, Slater CE, Engel MJ, Reynolds TF. Avoidable hospitalizations and socio-economic status in Galveston County, Texas. J Community Health 1994;19:377-87.

8 Bindman AB, Grumbach K, Osmond D, Komaromy M, Vranizan K, Luire $\mathrm{N}$, et al. Preventable hospitalizations and access to health care. JAMA 1995:274:305-11.

9 Billings J, Anderson GM, Newman LS. Recent findings on preventable hospitalizations. Health Affair (Millwood) 1996;15:239-49.

10 Weissman JS, Gatsonis C, Epstein AM. Rates of avoidable hospitalization by insurance status in Massachusetts and Maryland. JAMA 1992;268:2388-94.

11 Aveyard P. Monitoring the performance of general practices. J Eval Clin Pract 1997;3:275-81.
12 Farmer A, Coulter A. Organization of care for diabetic patients in general practice: influence on hospital admissions. Br J Gen Pract 1990;40:56-8.

13 Griffiths C, Sturdy P, Naish J, Omar R, Dolman S, Feeder G. Hospital admissions for asthma in east London: associations with characteristics of local general practices, prescribing, and population. BMJ 1997:314:482-6.

14 Watts JP, Cowmen P, Lewis RA. The relationship between asthma admission rates, routes of admission, and socio-economic deprivation. Eur Resp J 1996;9:2087-93.

15 Durojaiye LIA, Hutchison T, Madeley RJ. Improved primary care does not prevent the admission of children to hospital. Public Health 1989;103:181-8.

16 Casanova C, Starfield B. Hospitalizations of children and access to primary care: a cross-national comparison. Int J Health Services 1995;25:283-94.

17 Baker D, Klein R. Explaining outputs of primary health care: population and practice factors. BMJ 1991;303:225-9.

18 Carr-Hill RA, Hardman G, Martin S, Peacock S, Sheldon TA, Smith P. A formula for distributing NHS revenues based on small area use of hospital beds. York: Centre for Health Economics, University of York 1994. (Occasional Paper.)

19 White $\mathrm{H}$. A heteroskedasticity consistent covariance matrix and a direct test for heteroskedasticity. Econometrica 1978;46:817-38.

20 MacKinnon JG, White H, Davidson R. Tests for model specification in the presence of alternative hypotheses: some further results. $J$ Econometrics 1983;21:53-70.

21 McColl A, Roderick P, Gabbay J, Smith H, Moore M. Performance indicators for primary care groups: an evidence based approach. BMJ $1998 ; 317: 1354-60$

22 Moore AT. Roland MO. How much variation in referral rates among general practitioners is due to chance. BMJ 1989;298:500-2.

23 Marshall EC, Spiegelhalter DJ. Reliability of league tables of in vitro fertilisation clinics: retrospective analysis of live birth rates. BMJ 1998;316:1701-4.

24 NHS Executive. Health services indicators handbook 1994. Leeds: NHSE, 1994.

(Accepted 26 March 1999)

\title{
Explaining variation in hospital admission rates between general practices: cross sectional study
}

Fiona D A Reid, Derek G Cook, Azeem Majeed

Editorial by

Jankowski

Department of

Public Health

Sciences,

St George's

Hospital Medical

School, London

SW17 0RE

Fiona D A Reid,

lecturer in medical

statistics

Derek G Cook,

professor of

epidemiology

Department of

General Practice

and Primary Care,

St George's

Hospital Medical

School

Azeem Majeed,

senior lecturer in

general practice

Correspondence to:

F D A Reid

freid@sghms.ac.uk

BMJ 1999;319:98-103

\begin{abstract}
Objectives To quantify the extent of the variation in hospital admission rates between general practices, and to investigate whether this variation can be explained by factors relating to the patient, the hospital, and the general practice.

Design Cross sectional analysis of routine data. Setting Merton, Sutton, and Wandsworth Health Authority, which includes areas of inner and outer London.
\end{abstract}

Subjects 209136 hospital admissions in 1995-6 in patients registered with 120 general practices in the study area.

Main outcome measures Hospital admission rates for general practices for overall, emergency, and elective admissions.

Results Crude admission rates for general practices displayed a twofold difference between the 10th and the 90th centile for all, emergency, and elective admissions. This difference was only minimally reduced by standardising for age and sex. Sociodemographic patient factors derived from census data accounted for $42 \%$ of the variation in overall admission rates; $45 \%$ in emergency admission rates; and 25\% in elective admission rates. There was a strong positive correlation between factors related to deprivation and emergency, but not elective, admission rates, raising questions about equity of provision of health care. The percentage of each practice's admissions to different local hospitals added significantly to the explanation of variation, while the general practice characteristics considered added very little.

Conclusions Hospital admission rates varied greatly between general practices; this was largely explained by differences in patient populations. The lack of significant factors related to general practice is of little help for the direct management of admission rates, although the effect of sociological rather than organisational practice variables should be explored further. Admission rates should routinely be standardised for differences in patient populations and hospitals used.

\section{Introduction}

Large variations have been observed between British general practices in several measures relating to the process and outcome of health care, including outpatient referrals, ${ }^{1-7}$ uptake of breast screening, ${ }^{8}$ uptake of cervical screening, ${ }^{9}$ prescribing patterns, ${ }^{10}{ }^{11}$ and night visits. ${ }^{12}{ }^{13}$ Variations in hospital inpatient admission rates have been investigated for specific subgroups such as patients with asthma ${ }^{14}{ }^{15}$ and children. ${ }^{16}$ No study has yet examined, however, the extent of, or 
the reasons for, the variation in overall hospital admission rates.

If variation in admission rates cannot be accounted for by differences in patient morbidity or by artefacts in data, then questions arise regarding equity of access to hospital care, appropriateness of hospital referrals and admissions, and effectiveness of primary care. The current transfer of control to the primary care sector against a background of increasing admission rates ${ }^{17}$ highlights the need for research in this subject. We quantified the extent of the variation in hospital admission rates between general practices and investigated whether this variation can be explained by factors relating to the patient, the hospital, and the general practice.

\section{Methods}

Data were initially collected on all 133 general practices accountable to Merton, Sutton, and Wandsworth Health Authority in south London in April 1996.

Hospital admissions - Information on hospital inpatient admissions was obtained from the South Thames Regional Health Authority's patient information database, which collated data on all residents of South Thames admitted to NHS hospitals throughout England and Wales. Completed hospital spells that resulted in a discharge between January 1995 and December 1996 were selected, and admissions rather than episodes were counted. Admissions with a length of stay over 1 year were excluded to remove patients whose care may have been influenced by earlier configurations of partners. When the patient's general practice code was missing, a practice was allocated on the basis of the general practitioner code, when available, or by matching the age, sex, and postcode of the patient with information from the age-sex register. Around half the missing practice codes were imputed in this way.

Age-sex register data-The age, sex, and postcode of patients registered with general practices in April 1996 were obtained from the health authority's age-sex register. Detailed information was available only for residents of Merton, Sutton and Wandsworth, and all analyses were restricted to this subset of patients.

Sociodemographic profile of patient populationsEnumeration district data from the 1991 census were allocated to patients on the basis of their postcode and averaged across practice populations to give proxy sociodemographic variables for each practice. ${ }^{18}$ Definitions of the census variables used are given elsewhere. ${ }^{9}$

General practice and hospital variables-The health authority provided data on general practitioners and general practices relating to mid-1996. Data for individual general practitioners were summed or averaged as appropriate to provide a single figure per practice. The proportion of each practice's admissions to each of the six main local general hospitals was calculated.

Exclusions-Thirteen general practices were excluded: three were set up during 1995; nine had large fluctuations in the number of registered patients during the study period because of practice splits and other partnership changes; and the patients of one practice were all living in a nursing home. There remained 120 practices for analysis.

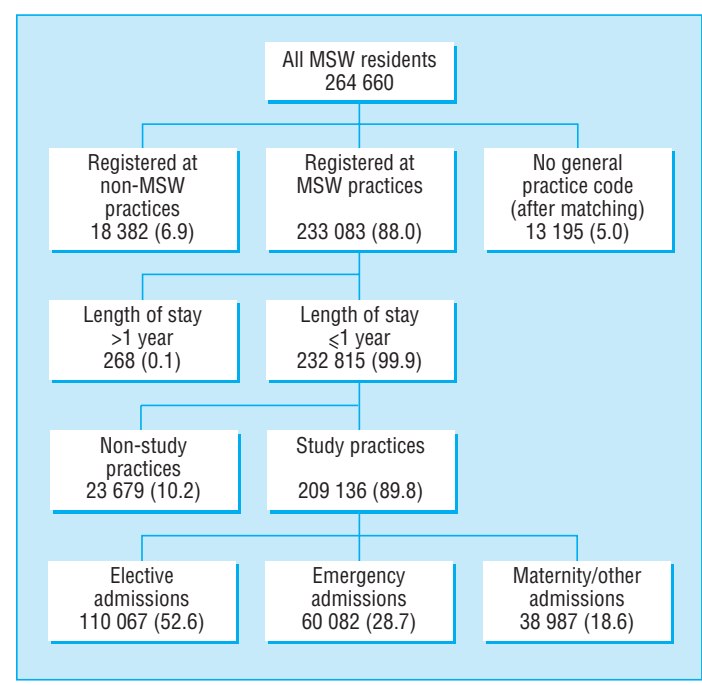

Fig 1 Numbers (\%) of admissions that resulted in discharge during 1995-6 for residents of Merton, Sutton, and Wandsworth Health Authority (MSW)

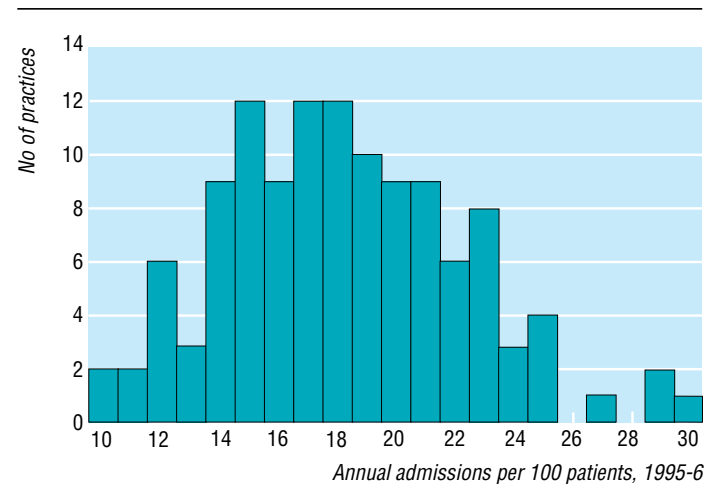

Fig 2 Crude admission rates for practices

Calculation of admission rates-Crude annual admission rates are defined as the number of admissions for each general practice per year per 100 patients registered at that practice. Admission ratios standardised for age and sex were calculated by the indirect method $^{19}$; numbers greater than 100 represent more admissions than expected and numbers less than 100 represent fewer admissions than expected. Standardised admission ratios are hereafter also referred to as standardised admission rates.

Statistical analysis-The association between admission rates and possible explanatory factors was investigated with Pearson's correlation for continuous variables; $t$ tests to compare means between the groups formed by categorical variables; and forward stepwise multiple regression for multivariate modelling. Admission rates were all normally distributed. Spearman's rank correlation was used to investigate associations with the percentage of admissions to different hospitals, however, because several of these variables were highly skewed. Analyses were conducted with SPSS for Windows, version $6.1 .^{20}$

\section{Results}

\section{Admission rates}

Figure 1 shows the numbers of admissions included and excluded in the study. The distributions of crude 
Table 1 Crude and standardised admission rates for practices in 1995-6

\begin{tabular}{lcrrr} 
& & & \multicolumn{2}{c}{ Centiles } \\
\cline { 4 - 5 } Type of admission & Mean (SD); 95\% Cl & Range & 10th & 90th \\
\hline Crude rates per 100 patients per annum: & & & \\
\hline All admissions & $18.2(4.1) ; 17.5$ to 19.0 & $10.1-29.6$ & 13.4 & 23.5 \\
\hline Emergency & $5.3(1.4) ; 5.0$ to 5.5 & $2.4-10.0$ & 3.7 & 7.0 \\
\hline Elective & $9.6(2.7) ; 9.1$ to 10.1 & $4.0-19.6$ & 6.7 & 13.4 \\
\hline Age-sex standardised ratios: & & & & \\
\hline All admissions & $100.3(19.7)$ & $60.9-149.3$ & 75.8 & 127.3 \\
\hline Emergency & $100.5(21.6)$ & $50.9-170.8$ & 77.5 & 131.1 \\
\hline Elective & $99.7(24.3)$ & $53.0-180.6$ & 69.7 & 134.7 \\
\hline
\end{tabular}

and age-sex standardised admission rates across practices are summarised in table 1 , and figure 2 shows the shape of the distribution for crude overall admission rates. The ratio of the 90th centile to the 10 th centile shows about a twofold difference in crude admission rates between practices for all, emergency, and elective admissions, while the ratio of the maximum to minimum rates is between threefold and fivefold. Standardisation of the admission rates for differences in the age and sex distributions of practices reduced the ratio of maximum to minimum rates to a factor of between 2.5 and 3.5, with only a slight reduction in the spread between the 10th and 90th centiles. The correlation between crude and standardised rates for all admissions was high $(r=0.95 ; \mathrm{P}<0.001)$, indicating little change in the ranking of practices by standardising for age and sex. There was also a strong positive correlation between standardised elective and emergency admission rates $(r=0.64 ; \mathrm{P}<0.001)$.

\section{Univariate analyses}

Significant correlations with age-sex standardised admission rates were found for many of the patient factors derived from the census, including the proportion chronically ill, who moved house in the last year, who were unskilled, and of one parent families (table 2). In general larger correlations were observed for emergency rather than elective admission rates. The proportion of admissions to three local general hospitals were each significantly associated with admission rates, with an inverse relation for two hospitals and a positive relation for the third. Of the 18 variables related to the general practice that were investigated, the only significant result was that fundholders had lower emergency admission rates (tables 3 and 4). Given the strong links between patient factors and admission rates, however, the meaning of the univariate associations with hospital and practice factors is unclear, and multivariate analysis is required.

\section{Multivariate analyses}

The first factors added to the multivariate model were those related to patients, followed by factors related to hospital and then general practice, reflecting the need to model variables that are effectively fixed before inclusion of those that are more capable of being

Table 2 Mean (SD) figures for patient factors and association between patient factors and standardised admission rates

\begin{tabular}{|c|c|c|c|c|c|c|c|}
\hline \multirow[b]{2}{*}{ Factor } & \multirow[b]{2}{*}{ Mean (SD) } & \multicolumn{2}{|c|}{ All admissions } & \multicolumn{2}{|c|}{ Emergency admissions } & \multicolumn{2}{|c|}{ Elective admissions } \\
\hline & & $r^{*}$ & $P$ value & $r^{*}$ & $P$ value & $r^{*}$ & $P$ value \\
\hline \multicolumn{8}{|c|}{ Jarman UPA8 components (\%): } \\
\hline Moved in past year & $12.8(2.9)$ & -0.46 & $<0.001$ & -0.31 & 0.001 & -0.36 & $<0.001$ \\
\hline Unskilled & $2.5(1.1)$ & 0.39 & $<0.001$ & 0.52 & $<0.001$ & 0.29 & 0.001 \\
\hline One parent families & $4.9(2.6)$ & 0.32 & $<0.001$ & 0.52 & $<0.001$ & 0.21 & 0.019 \\
\hline Elderly living alone & $6.1(1.2)$ & 0.29 & 0.001 & 0.28 & 0.002 & 0.28 & 0.002 \\
\hline Children aged under 5 & $6.6(1.2)$ & 0.28 & 0.002 & 0.20 & 0.026 & 0.14 & 0.12 \\
\hline Unemployed & $10.2(3.1)$ & 0.22 & 0.016 & 0.46 & $<0.001$ & 0.16 & 0.091 \\
\hline Overcrowded & $6.8(2.7)$ & 0.15 & 0.10 & 0.33 & $<0.001$ & 0.12 & 0.21 \\
\hline Born in NCP & $14.2(7.9)$ & -0.12 & 0.19 & -0.01 & 0.92 & -0.11 & 0.24 \\
\hline \multicolumn{8}{|l|}{ Other census variables (\%): } \\
\hline Chronically ill & $11.3(1.8)$ & 0.49 & $<0.001$ & 0.59 & $<0.001$ & 0.43 & $<0.001$ \\
\hline Not owner occupied & $35.1(14.4)$ & 0.19 & 0.043 & 0.45 & $<0.001$ & 0.14 & 0.14 \\
\hline No car & $29.2(9.4)$ & 0.13 & 0.16 & 0.40 & $<0.001$ & 0.10 & 0.28 \\
\hline Asian & $6.8(4.0)$ & -0.11 & 0.23 & -0.11 & 0.23 & -0.09 & 0.35 \\
\hline Non-white & $16.5(9.3)$ & -0.09 & 0.35 & 0.05 & 0.59 & -0.08 & 0.41 \\
\hline Black & $7.4(5.8)$ & -0.04 & 0.67 & 0.16 & 0.077 & -0.05 & 0.60 \\
\hline Jarman UPA8 score & $16.5(11.3)$ & 0.28 & 0.002 & 0.46 & $<0.001$ & 0.20 & 0.028 \\
\hline Townsend score & $0.7(2.6)$ & 0.18 & 0.046 & 0.44 & $<0.001$ & 0.14 & 0.13 \\
\hline
\end{tabular}

${ }^{*} r=$ Pearson's correlation coefficient. NCP=New Commonwealth and Pakistan.

Table 3 Mean (SD) figures for general practice factors and association between general practice factors and standardised admission rates

\begin{tabular}{|c|c|c|c|c|c|c|c|}
\hline \multirow[b]{2}{*}{ Factor } & \multirow[b]{2}{*}{ Mean (SD) } & \multicolumn{2}{|c|}{ All admissions } & \multicolumn{2}{|c|}{ Emergency admissions } & \multicolumn{2}{|c|}{ Elective admissions } \\
\hline & & $r^{*}$ & $P$ value & $r^{*}$ & P value & $r^{*}$ & $P$ value \\
\hline Cervical smear uptake (\%) & $75.8(11.7)$ & 0.14 & 0.13 & 0.05 & 0.62 & 0.15 & 0.11 \\
\hline Average age of GPs (years) & $49.4(8.0)$ & -0.04 & 0.67 & 0.03 & 0.78 & -0.10 & 0.27 \\
\hline No of partners & $2.6(1.7)$ & -0.07 & 0.46 & -0.07 & 0.43 & -0.03 & 0.77 \\
\hline Patients per GP & $2162(621)$ & 0.02 & 0.81 & 0.01 & 0.97 & 0.07 & 0.45 \\
\hline Generic prescribing ( $\%$ of total) & $59.6(10.2)$ & 0.05 & 0.59 & 0.05 & 0.60 & 0.05 & 0.62 \\
\hline Ratio of corticosteroids to bronchodilators & $0.42(0.10)$ & -0.01 & 0.98 & -0.01 & 0.98 & 0.04 & 0.64 \\
\hline Distance from nearest general hospital $(\mathrm{km})$ & $2.2(0.9)$ & 0.13 & 0.16 & 0.11 & 0.25 & 0.15 & 0.10 \\
\hline
\end{tabular}


Table 4 Association between general practice factors and standardised admission ratios

\begin{tabular}{|c|c|c|c|c|c|c|}
\hline \multirow[b]{2}{*}{ Factor and No of practices } & \multicolumn{2}{|c|}{ All admissions } & \multicolumn{2}{|c|}{ Emergency admissions } & \multicolumn{2}{|c|}{ Elective admissions } \\
\hline & Mean SAR & $P$ value & Mean SAR & $P$ value & Mean SAR & $P$ value \\
\hline \multicolumn{7}{|l|}{ Single handed practice: } \\
\hline Yes (40) & 97.8 & \multirow{2}{*}{0.32} & 99.6 & \multirow{2}{*}{0.74} & 95.5 & \multirow{2}{*}{0.18} \\
\hline No $(80)$ & 101.6 & & 100.9 & & 101.8 & \\
\hline \multicolumn{7}{|l|}{ Female partner in practice: } \\
\hline Yes (72) & 100.9 & \multirow{2}{*}{0.69} & 101.1 & \multirow{2}{*}{0.71} & 101.0 & \multirow{2}{*}{0.49} \\
\hline No (48) & 99.4 & & 99.6 & & 97.8 & \\
\hline \multicolumn{7}{|l|}{ Fundholder by April 1996: } \\
\hline Yes (38) & 97.1 & \multirow{2}{*}{0.24} & 94.6 & \multirow{2}{*}{0.040} & 96.6 & \multirow{2}{*}{0.34} \\
\hline No (82) & 101.7 & & 103.2 & & 101.2 & \\
\hline \multicolumn{7}{|l|}{ Practice manager: } \\
\hline Yes (84) & 98.8 & \multirow{2}{*}{0.20} & 99.0 & \multirow{2}{*}{0.24} & 98.7 & \multirow{2}{*}{0.50} \\
\hline No (36) & 103.8 & & 104.0 & & 102.0 & \\
\hline \multicolumn{7}{|l|}{ Practice nurse: } \\
\hline Yes (101) & 100.7 & \multirow{2}{*}{0.62} & 101.6 & \multirow{2}{*}{0.21} & 100.1 & \multirow{2}{*}{0.78} \\
\hline No (19) & 98.3 & & 94.8 & & 97.8 & \\
\hline \multicolumn{7}{|l|}{ On minor surgery list: } \\
\hline Yes (77) & 100.5 & \multirow{2}{*}{0.87} & 100.1 & \multirow{2}{*}{0.78} & 101.3 & \multirow{2}{*}{0.39} \\
\hline No (43) & 99.9 & & 101.2 & & 96.9 & \\
\hline On obstetrics list: & & & & & & \\
\hline Yes (107) & 99.9 & 0.49 & 100.1 & 0.58 & 99.8 & 0.97 \\
\hline No (13) & 103.9 & 0.49 & 103.6 & 0.58 & 99.5 & 0.97 \\
\hline On child health surveillance & & & & & & \\
\hline Yes (98) & 101.3 & ०?? & 101.7 & 020 & 101.2 & 016 \\
\hline No (22) & 95.7 & 0.22 & 95.2 & 0.20 & 93.2 & 0.10 \\
\hline In vocational training schem & & & & & & \\
\hline Yes (19) & 100.7 & 0.92 & 102.6 & 064 & 101.0 & 081 \\
\hline No (101) & 100.2 & 0.92 & 100.1 & 0.04 & 99.5 & 0.01 \\
\hline Teach medical students: & & & & & & \\
\hline Yes (12) & 97.3 & 058 & 94.6 & 0.32 & 95.4 & 032 \\
\hline No (108) & 100.6 & 0.50 & 101.1 & 0.02 & 100.2 & 0.02 \\
\hline Standard of premises: & & & & & & \\
\hline OK (66) & 100.2 & 0.85 & 100.4 & 0.80 & 99.4 & 079 \\
\hline Poor (52) & 100.9 & 0.00 & 101.4 & 0.80 & 100.7 & 0.19 \\
\hline
\end{tabular}

SAR=standardised admission ratio.

changed. For both overall and emergency admission rates three patient factors emerged as independently significant-namely, the proportion chronically ill, the proportion unskilled (both positively related to admission rates), and the proportion who moved house in the past year (negatively related). These three factors together accounted for $41.5 \%$ and $45.0 \%$ of the variation in overall and emergency admission rates, respectively. For elective admission rates only the proportion chronically ill and the proportion who moved house in the past year were independently significant, accounting for $25.1 \%$ of the variation.

The fit of each of the three models was improved by adding the proportion of admissions to the six local general hospitals (all admissions $F_{6,10}=2.96 ; \mathrm{P}=0.010$; emergency admissions $F_{6,110}=3.84 ; \mathrm{P}=0.002$; elective admissions $\left.F_{6,111}=2.42 ; \mathrm{P}=0.031\right)$. The total variation explained by the models increased to $49.6 \%, 54.5 \%$, and $33.7 \%$ for all admissions, emergency admissions, and elective admissions, respectively.

Three general practice variables produced a small but significant improvement in the fit of the models - namely, the practice's rate of uptake for cervical smears (all three models), child health surveillance offered (all admissions plus emergency), and minor surgery offered (all admissions plus elective). Each of these variables was positively correlated with admission rates. As these practice variables were strongly confounded with one another, only the single most significant factor was added to each model (table 5). These final models explained 53.5\%, 57.2\%, and 36.8\% of the variation in all, emergency, and elective admission rates, respectively.

\section{Discussion}

This study confirms that there is substantial variation in hospital admission rates between general practices,

Table 5 Multiple regression models for standardised admission rates

\begin{tabular}{|c|c|c|c|}
\hline Factors included in model & Coefficient* & $P$ value & $\begin{array}{c}\% \text { of variation } \\
\text { explained }\end{array}$ \\
\hline \multicolumn{4}{|l|}{ Overall admissions model†: } \\
\hline Chronically ill (\%) & 2.72 & 0.012 & \multirow{4}{*}{53.5} \\
\hline Unskilled (\%) & 5.66 & $<0.001$ & \\
\hline Moved in past year (\%) & -2.19 & $<0.001$ & \\
\hline Cervical smear uptake (\%) & 0.36 & 0.008 & \\
\hline \multicolumn{4}{|l|}{ Emergency admissions model†: } \\
\hline Chronically ill (\%) & 2.35 & 0.039 & \multirow{4}{*}{57.2} \\
\hline Unskilled (\%) & 6.41 & $<0.001$ & \\
\hline Moved in past year (\%) & -2.83 & $<0.001$ & \\
\hline Child health surveillance offered (Y/N) & 9.50 & 0.009 & \\
\hline \multicolumn{4}{|l|}{ Elective admissions model†: } \\
\hline Chronically ill (\%) & 4.93 & $<0.001$ & \multirow{3}{*}{36.8} \\
\hline Moved in past year (\%) & -2.78 & 0.003 & \\
\hline Minor surgery offered $(\mathrm{Y} / \mathrm{N})$ & 9.34 & 0.022 & \\
\hline
\end{tabular}

*Meaning of coefficients: for example, an increase of $1 \%$ in percentage chronically ill implies an increase of 2.72 in the age-sex standardised ratio for overall admissions.

†All models include practices' proportion of admissions to each of six local general hospitals. 
with a doubling between the 10th and 90th centiles of crude admission rates. Little of the variation observed in admission rates could be due to sampling variation as the rates were based on large numbers of admissions over 2 years. Previous studies have reported larger differences for both referral and admission $\operatorname{rates}^{235715}$; however, they generally presented the range of observed values, which is inappropriate as it reflects outliers and increases with sample size.

\section{Patient characteristics}

Patient factors were by far the most important in explaining the variation in admission rates, particularly for emergency admissions, when they accounted for $45 \%$ of the variation. The patient variables were calculated from census data, which are now out of date, and provide only proxy measures on the basis of the patient's postcode. Therefore it seems likely that the true effects of these variables may be even larger than the strong associations found here. If fair and meaningful comparisons are to be made between general practices, then hospital admission rates must routinely be adjusted for differences in patient populations.

The significant patient factors found suggest the following interpretations: the proportion of chronically ill patients reflects underlying morbidity, which is in turn closely linked to deprivation; the proportion unskilled suggests a further deprivation effect; and the proportion who moved house in the past year may be explained by higher list inflation among practices based in areas of higher mobility, resulting in artificially reduced admission rates for these practices. Deprivation may affect admission rates directly through increased morbidity, or indirectly through later presentation resulting in more acute symptoms or by lack of social support at home forcing admission. That elective admission rates were not related to the proportion unskilled might be explained by the counteracting effect of patients in more affluent areas having greater ability to access services and in particular to influence the referral decision of their general practitioner. This apparently greater association of deprivation with emergency than with elective admission rates raises issues of equity of healthcare provision, which deserve further investigation. ${ }^{21}$ The Jarman UPA8 score was less useful than a number of individual census variables in predicting admission rates, emphasising the limited value of this score in reflecting deprivation or workload for allocation of resources. ${ }^{22}$

\section{General practice characteristics}

By contrast, general practice factors explained only a tiny proportion of the variation, providing little help for health authorities or primary care groups in considering how to influence admission rates. The variables which were significant-cervical screening uptake rates, minor surgery offered, and child health surveillance offeredmight be considered proxies for quality. It is therefore surprising that these variables were positively correlated with both emergency and elective admission rates. Contrary to commonly held beliefs, emergency admission rates were not higher for fundholders.

This study focused on organisational practice variables available from routine data. Future studies should explore whether the remaining variation can be
- There is substantial variation in hospital admission rates between general practices

- Patient factors were by far the most important in explaining this variation whereas general practice characteristics explained a negligible amount, providing little help to those with an interest in managing admissions

- Deprivation was more strongly related to emergency rather than to elective admission rates, raising issues around equity of healthcare provision

- Admission rates should be standardised for differences in patient populations and hospitals used to give fair and meaningful comparisons between general practices

- Improvements in the quality of routine health services data are essential to enable health authorities and primary care groups to interpret information correctly

explained by psychological and sociological factors relating to the thinking and behaviour of individual general practitioners and the interaction between doctor and patient. Reasons previously suggested for variation in referral behaviour include the ability to live with uncertainty, ability to manage patient pressure, relationships with local consultants, and previous complaints from patients. ${ }^{53}$

Almost $10 \%$ of the variation in admission rates was explained by the use of different local general hospitals. This is probably an artefact arising from differential undercoding of the patient's general practice by different providers as the two hospitals linked to lower admission rates are known to have the biggest problem with missing practice codes. Alternative explanations would be different admission policies or a further area deprivation effect. It is important that comparative data on admission rates take account of differences between general practices related to provider as well as patient.

\section{Data quality}

One strength of the study is that the area covered by Merton, Sutton, and Wandsworth Health Authority is varied in terms of deprivation and affluence, covering both the urban and suburban. The limitations of the study are those associated with the use of routine data and highlight the need for improving data quality. Only patients resident in the health authority area could be included, leaving some border practices represented by a subset of their patients. More representative data could be analysed if adjacent health authorities shared information on patients living near their boundaries. The problems of list inflation in patient registration data and of missing general practice codes in admissions data have partly been accounted for by including the variable "proportion who moved in the past year" and the six hospital variables, respectively. Nevertheless, efforts to improve the accuracy of patient registration data and to influence providers to code the full required minimum dataset 
for all admissions must continue. ${ }^{24}$ Greater quality assurance in the collection and production of routine health services data is essential at a time when primary care groups will increasingly be expected to understand and act on such information.

We thank Paul Baldwin, Juliet Laurance, Belinda Myles, and Ivor Evans of Merton, Sutton, and Wandsworth Health Authority for providing the general practice and hospital admissions data, and Jan Poloniecki of St George's Hospital Medical School for calculating census variables for general practices.

Contributors: All authors were involved in the planning of the study. FDAR collated and analysed the data and was the principal writer of the paper. All authors participated in interpreting the results and revising the paper. FDAR is the study guarantor.

Funding: FDAR is partly funded by Merton, Sutton, and Wandsworth Health Authority

Competing interests: None declared.

1 Wilkin D, Smith A. Explaining variation in general practitioner referral to hospital. Fam Pract 1987:4:160-9.

2 Crombie DL, Fleming DM. General practitioner referrals to hospital: the financial implications of variability. Health Trends 1988;20:53-6.

3 Noone A, Goldacre M, Coulter A, Seagroatt V. Do referral rates vary widely between practices and does supply of services affect demand? A study in Milton Keynes and the Oxford region. J R Coll Gen Pract 1989:39:404-7.

4 Coulter A, Seagroatt V, McPherson K. Relation between general practices' outpatient referral rates and rates of elective admission to hospital. BMJ 1990;301:273-6.

5 de Marco P, Dain C, Lockwood T, Roland M. How valuable is feedback of information on hospital referral patterns? BMJ 1993;307:1465-6.

6 Fertig A, Roland M, King H, Moore T. Understanding variation in referral among general practitioners: are inappropriate referrals important and would guidelines help to reduce rates? BMJ 1993;307:1467-70.

7 Hippisley-Cox J, Hardy C, Pringle M, Fielding K, Carlisle R, Chilvers C. The effect of deprivation on variations in general practitioners' referral rates: a cross-sectional study of computerised data on new medical and surgical outpatient referrals in Nottinghamshire. BMJ 1997;324:1458-61.
8 Majeed FA, Cook DG, Given-Wilson R, Vecchi P, Poloniecki J. Do general practitioners influence the uptake of breast cancer screening? J Med Screening 1995;2:119-24.

9 Majeed FA, Cook DG, Anderson HR, Hilton S, Bunn S, Stones C. Using patient and general practice characteristics to explain variations in cervical smear uptake rates. BMJ 1994;308:1272-6.

10 Majeed A, Cook D, Evans N. Variations in general practice prescribing costs-implications for setting and monitoring prescribing budgets. Health Trends 1996;28:52-5.

11 Whynes DK, Baines DL, Tolley KH. Explaining variations in genera practice prescribing costs per ASTRO-PU (age, sex, and temporary resident originated prescribing unit). BMJ 1996;312:488-9.

12 Majeed FA, Cook DG, Hilton S, Poloniecki J, Hagen A. Annual night visiting rates in 129 general practices in one family health services authority: association with patient and general practice characteristics. $\mathrm{Br} J \mathrm{Gen}$ Pract 1995;45:531-5.

13 Whynes DK, Baines DL. Explaining variations in the frequency of night visits in general practice. Fam Pract 1995;13:174-8

14 Griffiths C, Naish J, Sturdy P, Pereira F. Prescribing and hospital admissions for asthma in east London. BMJ 1996;312:481-2.

15 Griffiths C, Sturdy P, Naish J, Omar R, Dolan S, Feder G. Hospital admissions for asthma in east London: associations with characteristics of local general practices, prescribing, and population. BMJ 1997;314:482-6.

16 Thakker Y, Sheldon TA, Long R, MacFaul R. Paediatric inpatient utilisation in a district general hospital. Arch Dis Child 1994;70:488-92.

17 Capewell S. The continuing rise in emergency admissions. BM 1996;312:991-2.

18 Majeed FA, Cook DG, Poloniecki J, Martin D. Using data from the 1991 census. BMJ 1995;310:1511-4.

19 Armitage P, Berry G. Statistical methods in medical research. 2nd ed. Oxford: Blackwell Scientific Publications, 1987:403-5.

20 Norusis MJ. SPSS for Windows base system user's guide, release 6.0. Chicago: SPSS Inc, 1993.

21 Pollock AM, Vickers N. Deprivation and emergency admissions for cancers of colorectum, lung and breast in south east England: ecological study. $B M J$ 1998:317:245-52.

22 Carr-Hill RA, Sheldon T. Designing a deprivation payment for general practitioners: the UPA(8) wonderland. BMJ 1991;302:393-6.

23 Newton J, Hayes V, Hutchinson A. Factors influencing general practitioners' referral decisions. Fam Pract 1991;8:308-13.

24 Majeed A. Hospital admissions data: why are they collected? Clinician Manage 1998;7:160-6.

(Accepted 28 April 1999)

\section{A memorable patient No silent areas}

Many years ago I was sent by the Royal Navy to the then National Hospital for Nervous Diseases to sit at the feet of Dr William Gooddy, senior physician and civilian consultant to the navy and one of the great neurologists; happily now an old friend. Every Tuesday morning William held his grand round, beginning in a large room next to the sister's office, which could seat the 30 or so postgraduate students who regularly attended. One of the conventions at Queen Square is that difficult cases are sometimes offered to other firms for their opinion so that as many brilliant minds as possible may be brought to bear to help the patients.

On this occasion an artist was presented by the registrar of another firm, who explained that the man had gone to see his general practitioner complaining that he could no longer distinguish between paintings from his experience alone. His capacity to differentiate, say, a Rembrandt from a Renoir had left him. Other than this he felt entirely well. He had, in short, went on the registrar, lost his gestalt. I pursed the lips, put the tips of the fingers together, and tried in vain to look learned, hoping that someone would ask the question. They did.

"Gestalt, from the Middle High German word for shape or form," explained William, "means, in physical terms, that he has impaired appreciation that a physical or indeed emotional entity may be more than the sum of its constituent parts. In this case it is paintings which he cannot see as a whole." We all blinked and the registrar went on to explain that this was the only symptom that could be adduced. It had been confirmed clinically and all investigations had proved to be normal.

"Have you done a bronchoscopy?" William asked. The registrar could not keep a hint of elation out of his voice, "Oh yes, it showed nothing unusual."

"I should repeat it in three months," said William, and the round continued.
Afterwards I asked, why a bronchoscopy? William explained that he thought that this chap had a lesion in his parietal lobe, probably a secondary from a primary in the lung.

Some weeks later the same registrar, now with a little awe in his voice, told the Tuesday round that a second bronchoscopy had shown a small carcinoma in the left main bronchus. Some months later we were told that the unfortunate patient had died; a necropsy revealed a secondary the size of a pea in the right parietal lobe.

Discussing this later with William, I expressed my doubts about ever being able to get to grips with neurology because so much of the brain seemed to be "silent" and to have little apparent relationship with the rest of the body.

"Oh no," said William with the generous smile of vast experience, "there are no silent areas in the brain. It is just that we don't yet know how to test them."

I was left with the thought that perhaps it is dysfunction of one of these "silent" areas that doesn't allow me to appreciate modern music. But then, as my wife remarked, how do you test gestalt in a nitwit?

\section{James Wright, retired physician, Yelverton, Devon}

We welcome articles up to 600 words on topics such as A memorable patient, A paper that changed my practice, My most unfortunate mistake, or any other piece conveying instruction, pathos, or humour. If possible the article should be supplied on a disk. Permission is needed from the patient or a relative if an identifiable patient is referred to. We also welcome contributions for "Endpieces," consisting of quotations of up to 80 words (but most are considerably shorter) from any source, ancient or modern, which have appealed to the reader. 